\title{
TESTS ON 10.9 BOLTS UNDER COMBINED TENSION AND SHEAR DURING AND AFTER FIRE
}

\author{
Anne K. Kawohl, Jörg Lange \\ TechnischeUniversität Darmstadt, Institute for Steel Structures and Material Mechanics, Darmstadt, Germany
}

\begin{abstract}
Prior investigations of the load bearing capacity of bolts during fire have shown differing behaviour between bolts that were loaded by shear or by tensile loads. The interaction of the two loads has not yet been examined under fire conditions. This paper describes a preliminary test series on the postfire performance of high-strength bolts of the property class 10.9 under combined tension and shear. The results show that how the bolt is loaded influences the load bearing capacity. It is assumed that this is also true at elevated temperatures. Further, atest set-up for experiments at elevated temperatures and a more detailed test series on the post-fire performance under combined tension and shear is presented.
\end{abstract}

Keywords: high-strength bolts, tension and shear, connections, experimental study

\section{INTRODUCTION}

Connections play a key role in steel structures as they not only join the different bearing members of a structure, but also transfer the loads from one member to the next. In the event of fire the connections play a critical role in the stability of the whole structure. Their failure can lead not only to the failure of individual connected members, but also, for example, to a change in buckling length of the entire structure and therefore to its collapse. The behaviour of joints in fire has been the focus of numerous investigations, (Al-Jabriet al., 2008) and (Burgess et al., 2012) give a good overview of the research in this field.

All of these investigations have in common that they examine the connections as a whole. In a connection there are many effects that come together and influence the load bearing behaviour at elevated temperatures. To understand these different effects, it is of importance to have a thorough knowledge of the load bearing behaviour of the individual elements of a connection, e.g. the bolts used. Appendix D of Eurocode 3 Part 1-2 (DIN EN 1993-1-2) states reduction factors for the strength of bolts at elevated temperatures. These reduction factors are independent of the property class of the bolts. As high-strength bolts of the property classes 8.8 and $10.9\left(f_{u}=800 \mathrm{~N} / \mathrm{mm}^{2}\right.$ or $1,000 \mathrm{~N} / \mathrm{mm}^{2}$ ) obtain their enhanced strength through different heat treatments, the assumption that these bolts behave in the same way as bolts of the property classes 4.6 and 5.6 at elevated temperatures must be questioned.

There are not as many studies on the load bearing behaviour of bolts at elevated temperatures as on complete connections, but they have become more frequent over the last few years. The tests conducted on bolts so far focus either on pure tension or pure shear. Up to now, the combination of both loads has not been examined specifically.(Kirby 1995) conducted extensive tests on grade 8.8 bolts. Among others, he tested different bolt sets at steady state conditions both under shear or tension. The test results show deviating reductions of the load bearing capacity of the bolts with reference to the temperature, depending on whether the bolts were loaded by tension or shear. The reduction factors in Eurocode 3 (DIN EN 1993-1-2) are based on the test results by (Kirby 1995). As stated in the ECCS Model Code on Fire Engineering (ECCS 2001), the reduction factors are based on the tensile tests as they result in more conservative values. (González 2011) conducted tests on 10.9 bolts both under pure tension and pure shear. The tests results of the tension tests showed that for temperatures exceeding $450^{\circ} \mathrm{C}$ the actual reduction factor lies significantly below the reduction factor given by the Eurocode 3 (DIN EN 1993-1-2). The gradient of the load bearing capacity of the bolts under shear differs from the gradient under tension. The load bearing 
capacityunder shear is overestimated by the Eurocode 3 only in the temperature range between $400^{\circ} \mathrm{C}$ and $600^{\circ} \mathrm{C}$. In addition to the analogy to Kirby concerning the difference between shear and tension, his test results clearly show that it is not conservative to use the reduction factors from Eurocode 3 for bolts of the property class 10.9. The tests on A325 and A490 bolts by (Kodur et al., 2012) show also a different descent of the load bearing capacity between shear and tension at rising temperatures, as well as a difference in behaviour between the two different grades of bolts.

In most connections used in steel structures the bolts are either strained by tension or shear. Nonetheless, connections with bolts strained by a combination of tension and shear cannot be disregarded. In addition, there is a possibility that during a fire, bolts that were designed to either carry tension or shear may be strained by a combination of these two due to the deflection of the connecting members caused by high temperatures. This can be seen in Figure 1whichshows two photographs of a production building damaged by fire. In the left photograph it is clearly visible how the connections to the column are distorted by the connected members. The photograph on the right shows a column base with a gap between the joining endplates due to the deflection of the column.

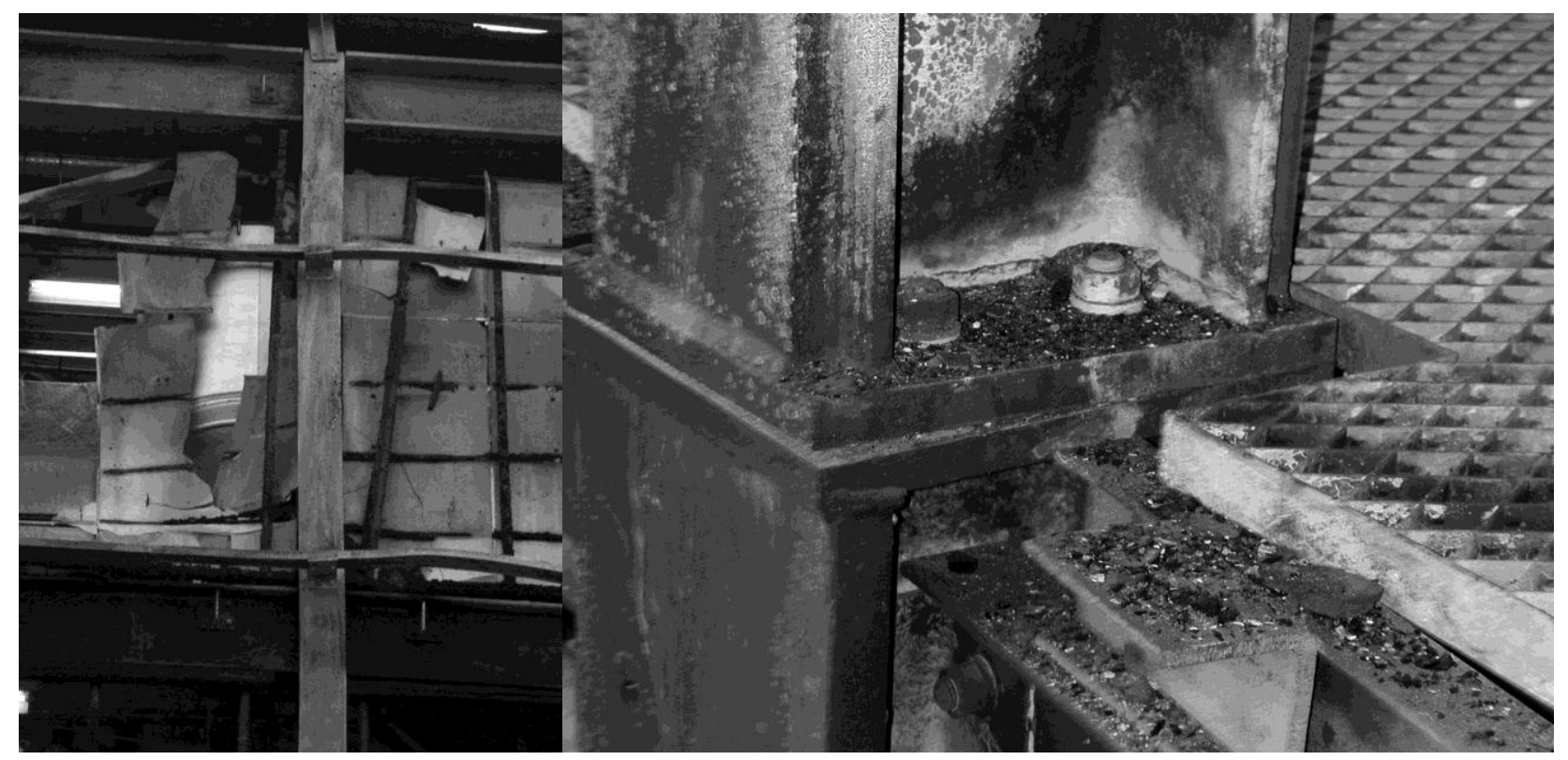

Fig. 1 Column with connecting members (left) and column base after fire damage in a production building

\subsection{Preliminary Post-Fire Tests}

A first small test series on the post-fire performance of 10.9 bolts has been carried out (Kawohl et al. 2014) to establish whether different combinations of shear and tension load have an influence on the load bearing capacity of the bolts, as can be assumed by the different gradients of the load bearing capacities stated above. For this test series M20 shank bolts of the property class 10.9 were heated to $500^{\circ} \mathrm{C}, 700^{\circ} \mathrm{C}, 800^{\circ} \mathrm{C}$ and $900^{\circ} \mathrm{C}$ and then slowly cooled to ambient temperature. Test rigs were used that were designed for a large experimental study on the interaction behaviour of bolts of different property classes at ambient temperature (Renner et al. 2012).With each of the three test rigs a bolt can be pulled in two different angles, each causing a different tension-to-shear relation. In Figure 2 the test rig for the angles $45^{\circ}$ and $0^{\circ}$ is shown. The test rig is set up for a test under an angle of $45^{\circ}$. The other tested angles were $15^{\circ}, 30^{\circ}, 67.5^{\circ}$ and $90^{\circ}$ (pure shear) and pure shear tests with two shear planes.

In addition to the failure load and the total displacement, the gap and the shift were measured between the two bolted slabs. For the evaluation of the load bearing capacity the failure loads are mainly of interest. The gap and shift were measured to verify whether the application fixtures had twisted or tilted in an unplanned manner. 


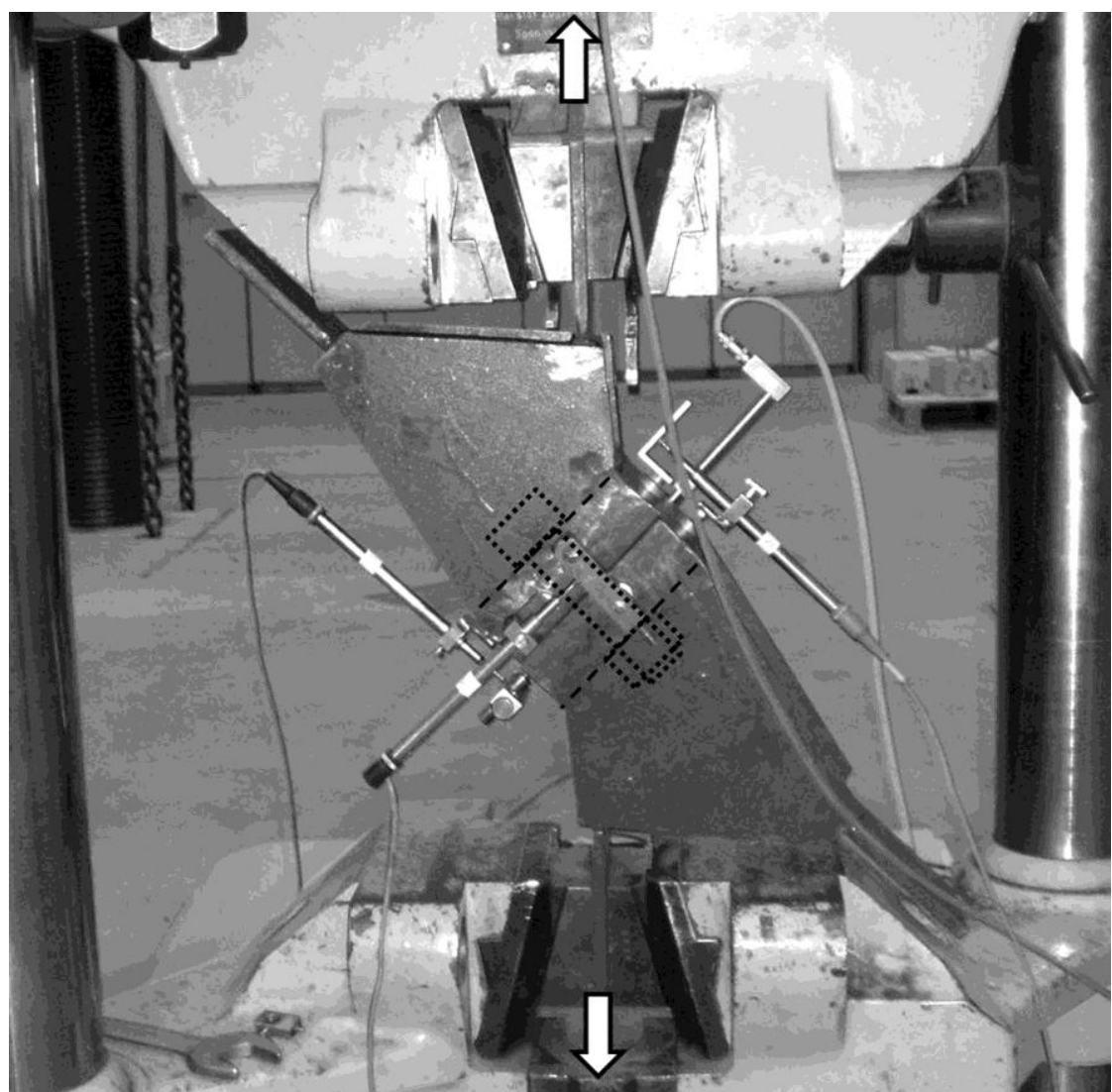

Fig. 2 Test rig for angles of $0^{\circ}$ and $45^{\circ}$ set up for an angle of $45^{\circ}$

For each angle and temperature one bolt was tested, with a few exceptions where two bolts were tested. The bolt was loaded, displacement-controlled, with $2 \mathrm{~mm} / \mathrm{min}$ until failure. The failure loads verify the assumption that how the load is applied does indeed influence the post-fire performance of the tested bolts depending on the temperature to which they were heated. Consequently the shearto-tension-coefficient $\alpha_{\mathrm{v}}$ is dependent on the temperature. Table 1 shows the tension-to-shear coefficients calculated from the test results.

Table 1 Calculated strength coefficient $\alpha_{\mathrm{v}}$

\begin{tabular}{|c|c|c|c|c|c|}
\hline Temperature & $20^{\circ} \mathrm{C}$ & $500^{\circ} \mathrm{C}$ & $700^{\circ} \mathrm{C}$ & $800^{\circ} \mathrm{C}$ & $900^{\circ} \mathrm{C}$ \\
\hline$\alpha_{\mathrm{v}}$ & 0.61 & 0.61 & 0.70 & 0.67 & 0.72 \\
\hline
\end{tabular}

In Figure 3 the failure loads are shown as a diagram. For a better comparison of the different temperatures lines were drawn between the measured values. When tested only with one shear plane the bolts were slightly inclined which results in higher load capacities. For that reason the values of the tests for the angle of $90^{\circ}$ with two shear planes were chosen for the diagram. As presumed by the findings of the stated researches in the beginning the reduction of the load bearing capacity is less for the bolts tested under pure shear (angle of $90^{\circ}$ ) than under pure tension (angle of $0^{\circ}$ ). Surprisingly, at an angle of $45^{\circ}$ - tension-shear-relation of 1.0 - the difference between the original load bearing capacity and the post fire performance is the smallest.

Taking into account the test results of the preliminary test series on post-fire performance and the observations made by (Kirby 1995), (González 2011) and (Kodur et al. 2012) it can be assumed that how the load is applied does also influence the load bearing capacities of bolts at elevated temperatures. To validate this assumption a test series at elevated temperatures as well as a more detailed test series on the post-fire performance of 10.9 bolts is planned. 


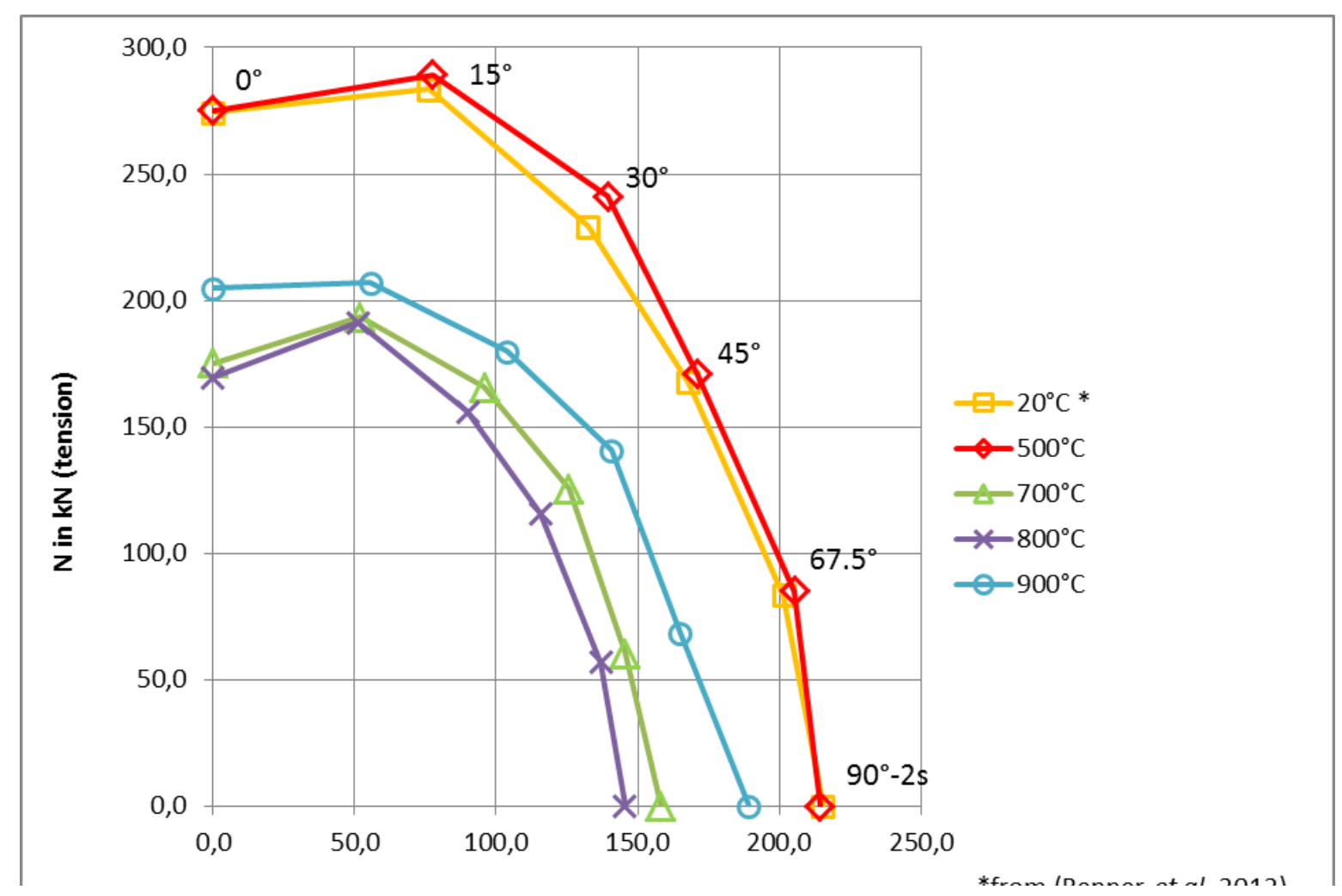

Fig. 3 Failure loads of M20 bolts grade 10.9 with shank in shear plane

\section{TEST SET-UP}

For the planned tests at elevated temperatures the test rigsdesigned by (Renner et al. 2012) are not practical, due to the boundary conditions of the furnace which is needed. However, the basic idea of applying load in only one direction but thereby straining the bolt both by tension (in the bolt axis) and shear (perpendicular to the bolt axis) through a suitable test rig at the same time should be retained. New test rigs that are based on this basic idea where designed, while at the same time taking into account that the furnace that is to be used for the tests only allows application of pressure. The design combines the principles of a compact test rig by (Godley et al. 1982), where tension tests in bolts were done by applying compression, and the use of different angles as in the tests rigs by (Renner et al. 2012). In Figure 4 the newly designed test rigs for an angle of $0^{\circ}$ (left), $30^{\circ}$ (centre) and $45^{\circ}$ (right) are shown. The upper and the lower frame of the test rig are joined only by the bolt to be tested in the centre. The bolt is stressed by applying compressionon the bottom and top plate of each test rig causing tension, for the angles of $30^{\circ}$ and $45^{\circ}$ also shear, in the bolt.
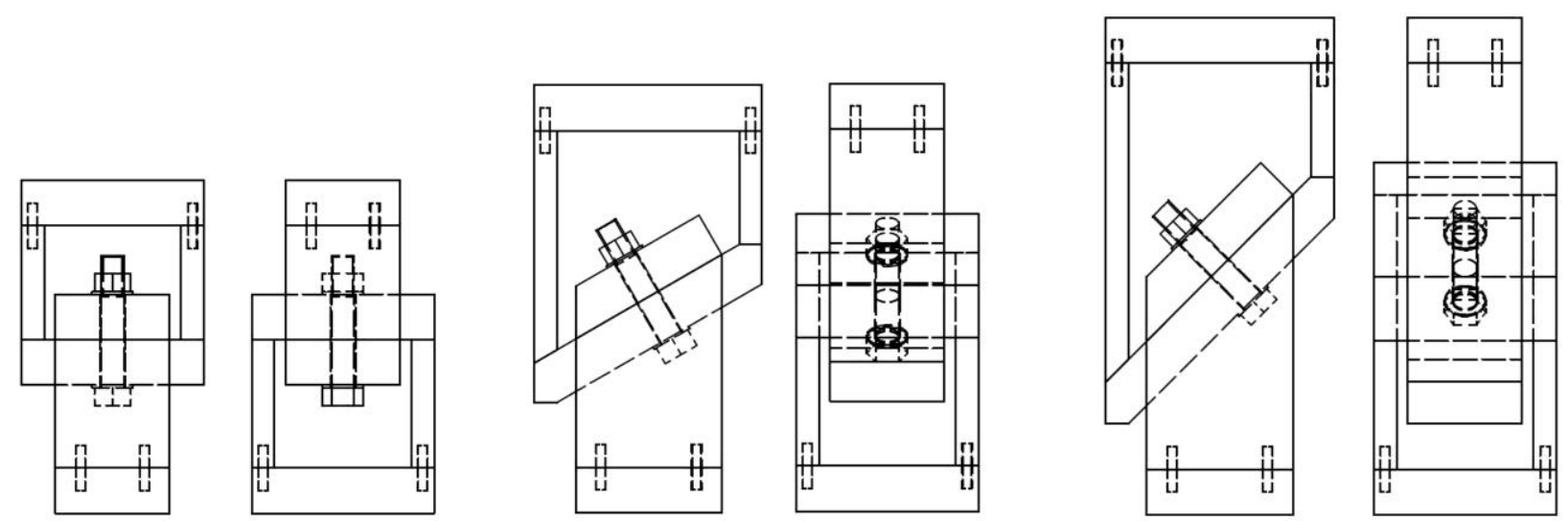

Fig. 4 Test rigs for an angle of $0^{\circ}$ (left), $30^{\circ}$ (centre) and $45^{\circ}$ (right) 


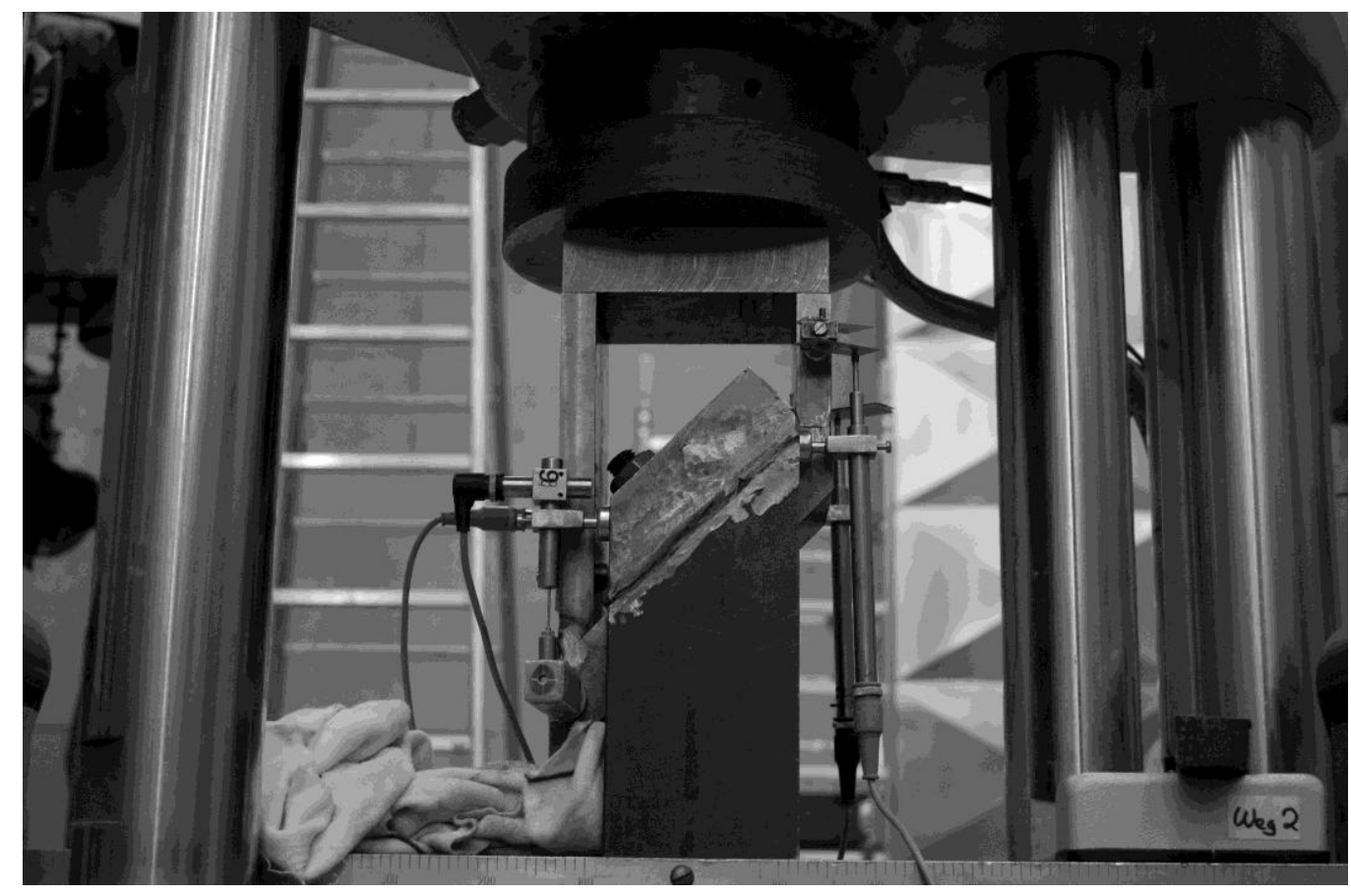

Fig. 5 Prototype of the new test rig for an angle of $45^{\circ}$

First a prototype with an angle of $45^{\circ}$ (Figure4, right) was built out of S355 construction steel to verifywhether it functions as predicted. The same bolts that were tested by Renner (Renner et al. 2012) were used in order to have a direct comparison of the test results. All tests were conducted at ambient temperature. The results of the bolts tested with the prototype of the new test rig (Figure5) do not totally match the results from Renner (Renner et al. 2012). This is mainly explained by the more rigid construction of the new test rig, where the displacements in horizontal direction are constrained by the friction between the testing rig and the compression machine. This causes a slightly different division into the strain in the bolt axis (tension) and perpendicular to the bolt axis (shear). Keeping this in mind, the new test rigs are nonetheless suitable for the planned tests at elevated temperatures. For these tests, they were built out of the nickel-based alloy NIMONIC@80A, a high-temperature alloy.The bolts to be tested are M20 shaft bolts of the property class 10.9 . Following the planned test layout for both the tests at elevated temperatures and the post-fire performance are described in more detail.

\subsection{Tests at Elevated Temperatures}

The tests will be conducted as steady-state tests with the temperature rising until the exposed bolt parts reach the specified temperature. The temperature is kept constant and after a stabilising time the bolt is loaded until failure. For the fire tests a 4 zone electric furnace with a maximum temperature of $1,000^{\circ} \mathrm{C}$ will be used. The furnace is fitted with a $3 \mathrm{MN}$ compression machine. Thermocouples of type $\mathrm{K}$ will be installed to monitor the temperature on the surface of the test rig as well as the bolt. The furnace has a heating rate of approximately $10 \mathrm{~K} / \mathrm{min}$. The temperature must be monitored carefully to ensure that the bolt is heated uniformly. The load will be applied in a displacement-controlled manner. As experimental studies in fire are both time-consuming and expensive only two temperatures are specified $500^{\circ} \mathrm{C}$ and $700^{\circ} \mathrm{C}$. For every combination of temperature and angle 3 tests will each be carried out.

\subsection{Post-Fire Performance Tests}

For the tests on the post-fire performance of the bolts the same test rigs are used as for the tests at elevated temperatures. As these tests are less time-consuming and expensive, a larger number of temperatures will be tested. Equivalent to the preliminary test series the bolts will be heated to 
$500^{\circ} \mathrm{C}, 700^{\circ} \mathrm{C}, 800^{\circ} \mathrm{C}$ and $900^{\circ} \mathrm{C}$ and cooled slowly at room temperature. The heating rate will be $10 \mathrm{~K} / \mathrm{min}$ and therefore the same as for the tests in fire. Once the bolts have reached the temperature aimed for, it will be kept constant for 30 min to ensure that the temperature is reached throughout the bolt section.

For the tests a compression machine with a maximum load of $1 \mathrm{MN}$ will be used. The test will be displacement-controlled at $1 \mathrm{~mm} / \mathrm{min}$ and the bolts loaded until failure. For every combination of temperature and angle 5 bolts will each be tested. In addition 5 bolts from the same batch will be tested without further heat treatment as reference.

\section{CONCLUSIONS}

During different tests on bolts it was observed that the load bearing capacity of high-strength bolts at elevated temperatures degrades differently when loaded by shear as opposed to being loaded by tension, (González 2011) and (Kodur et al. 2012). A preliminary test series on the post-fire performance of 10.9 bolts under combined tension and shear carried out by the authors has shown that the combination of the two different loads has an influence on the residual load bearing capacity. For a more thorough investigation an extended test series on the post-fire performance as well as steady state tests at elevated temperatures is planned.

\section{REFERENCES}

Al-Jabri, K.S., Davison, J.B., Burgess, I.W. 2008.Performance of beam-to-column joints in fire - A review. Fire Safety Journal, 43(2008), p. 50-62.

Burgess, I. W., Davison, J.B., Dong, G., Huang, S.-S. 2012. The Role of Connections in the Response of Steel Frames to Fire. Structural Engineering International, 4(2012), p. 449-461.

DIN EN 1993-1-2: Eurocode 3: Design of steel structures, Part 1-2: General rules - Structural Fire design. German Version; EN 1993-1-2; 2:2005 + AC:2009.

European Convention for Constructional Steelwork / Technical Committee Fire Safety of Steel Structures ECCS (2001).Model Code on Fire Engineering

González Orta, F., 2011. Untersuchungen zum Material- und Tragverhalten von Schrauben der Festigkeitsklasse 10.9 während und nach einem Brand, Dissertation, Technische Universität Darmstadt.

Godley, M.H.R.; Needham, F.H. 1982.Comparative tests on 8.8 and HSFG bolts in tension and shear. The Structural Engineer, 60(3), p. 94-99

Kawohl, A.; Renner, A.; Lange, J., 2014. Experimental Study of Post Fire Performance of High-strength Bolts under Combined Tension and Shear, $8^{\text {th }}$ International Conference on Structures in Fire, June 11-13, 2014, Shanghai, China, p. 89-96.

Kirby, B. R., 1995. The Behaviour of High-strength Grade 8.8 Bolts in Fire. Journal of Constructional Steel Research, 33(1995), p. 3-38.

Kodur, V., Kand, S., Khaliq, W., 2012. Effect of Temperature on Thermal and Mechanical Properties of Steel Bolts. Journal of Materials in Civil Engineering, 24 (6), p. 765-774.

Lange, J., González Orta, F., 2012. Behavior of High-Strength Grade 10.9 Bolts under Fire Conditions. Structural Engineering International, 4(2012), p. 470-475

Renner, A., Lange, J. 2012. Load-bearing behavior of high-strength bolts in combined tension and shear. Steel Construction, 5(3), p. 151-157. 